\title{
Numerical Analysis of an All-optical Logic XOR gate based on an active MZ interferometer
}

Nielsen, Mads Lønstrup; Mørk, Jesper; Fjelde, T.; Dagens, B.

Published in:

Summaries of Papers Presented at the Lasers and Electro-Optics, 2002. CLEO '02. Technical Digest.

Link to article, DOI:

10.1109/CLEO.2002.1034382

Publication date:

2002

Document Version

Publisher's PDF, also known as Version of record

Link back to DTU Orbit

Citation (APA):

Nielsen, M. L., Mørk, J., Fjelde, T., \& Dagens, B. (2002). Numerical Analysis of an All-optical Logic XOR gate based on an active MZ interferometer. In Summaries of Papers Presented at the Lasers and Electro-Optics, 2002. CLEO '02. Technical Digest. (Vol. 1). IEEE. https://doi.org/10.1109/CLEO.2002.1034382

\section{General rights}

Copyright and moral rights for the publications made accessible in the public portal are retained by the authors and/or other copyright owners and it is a condition of accessing publications that users recognise and abide by the legal requirements associated with these rights.

- Users may download and print one copy of any publication from the public portal for the purpose of private study or research.

- You may not further distribute the material or use it for any profit-making activity or commercial gain

- You may freely distribute the URL identifying the publication in the public portal 
References

1. D.J. Derickson, A. Mar, and J.E. Bowers "Residual and absolute timing jitter in actively modelocked semiconductor lasers", Electron. Lett. 26, 2026-2028 (1990).

2. D. Derickson, Fiber optic test and measurement (Prentice Hall PTR, Upper Saddle River, N.J., 1998), Chap. 5.

3. C.M. DePriest, A. Braun, J.H. Abeles, and P.J. Delfyett, Ir. "10-GHz ultra-low noise optical sampling stream from a semiconductor diode ring laser", IEEE Photonics Technol. Lett. 13, 1109-1111 (2001).

4. T. Yilmaz, C.M. DePriest, and P.J. Delfyett, Jr., "Complete noise characterization of an external cavity semiconductor laser hybridly modelocked at $10 \mathrm{GHz}$, Electron. Lett. 37, 1338-1339 (2001)

\section{CThAA}

4:45 pm-6:30 pm Room: $104 \mathrm{C}$

\section{Optical Signal Processing}

Fred Heismann, Atrium Networks, Inc., USA, Presider

CThAA1

4:45 pm

Numerical Analysis of an Altoptical

Logic XOR Gate Based on an Active MZ Interferometer

Mads Lonstrup Nielsen, Jesper Mork, Research Center COM, Technical University of Denmark, Oersteds Plads 343, DK-2800 Kgs. Lyngby,

Denmark,Email: mln@com.dtu.dk, jm@com.dtu.dk

Tina Fjelde, Mintera Corporation, 847 Rogers St., One Lowell Research Center, Lowell, MA. 01852, USA,Email: tina.fjelde@mintera.com

Beatrice Dagens, Alcatel Rer I, Route de Nozay, 91460 Marcoussis, France,

Email:Beatrice.dagen@ms.alcatel.fr

1. Introduction

The implementation of an all-optical exclusiveOR (XOR) gate is receiving a lot of attention ${ }^{1-4}$ due to its great potential as an optical comparator and decision circuit. One of the more promising devices for realizing XOR is the integrated SOAbased interferometric wavelength converter (IWC), offering compactness and stability, as well as high speed $(20+\mathrm{Gb} / \mathrm{s}){ }^{2}$ A vital issue for practical implementation of optical XOR gates is the tolerance of the gate towards imperfect synchronism of the two signals participating in the XOR operation, as well as the tolerance towards variations of the signal pulse widths. These issues are investigated numerically for a Mach-Zehnder interferometer (MZI) based XOR gate.

\section{XOR in a MZI: Principle of operation}

The MZI, shown in Fig. 1 a), is balanced in order to obtain minimum transmission of the $\mathrm{CW}$ light in the case of a logic zero in both input data signals. A logic one-bit in one of the data signals, e.g. D1, will cause a phase change of $\pi$ of the CW light in the upper arm, thereby switching the state of the MZI. A one-bit in both signals does not alter the state, and consequently the XOR truth-table is realized. In Fig. 1 b), experimental $R Z$ input data signals at $20 \mathrm{~Gb} / \mathrm{s}$, the experimental XOR output, ${ }^{2}$ and a corresponding simulated XOR output are shown.

\section{Modeling results}

The numerical analysis is based on a detailed model of the MZI, taking into account the temporal and spatial evolution of the signals and the ASE spectrum. To evaluate the performance of the XOR gate quantitatively, a direct detection receiver model comprising a detector, an electrical filter, and a BER-estimation is used. The input data signals D1 and D2 are PRB-sequences of length $2^{7}-1$. Fig. 2 a) and b) show the calculated power penalties for $R Z$ and NRZ signal formats, respectively, as a function of the synchronization delay between D1 and D2 at different bit-rates.

A delay of zero corresponds to a perfect timeslot alignment of the two signals. For RZ, a constant ratio of FWHM Gaussian-pulse width to timeslot of 0.2 is used at all bit-rates, and it is observed that a delay of $\approx \pm 0.4 \tau$, where $\tau$ is the pulse width, can be tolerated while keeping the penalty below $1 \mathrm{~dB}$, independent of bit-rate. For NRZ, the tolerance is $\approx \pm T / 2$ for 10 and $20 \mathrm{~Gb} / \mathrm{s}$, where $\mathrm{T}$ is the timeslot. At $40 \mathrm{~Gb} / \mathrm{s}$, the finite rise/fall-time of 15 ps becomes a limiting factor. Assuming perfect timeslot synchronism, the RZ pulse width of D1 has been varied by $\Delta \tau$ compared to $\mathrm{D} 2$, while keeping the average power constant. The $1 \mathrm{~dB}$ penalty-tolerance is $\approx \pm 0.8 \tau$ for both 20 and 40 $\mathrm{Gb} / \mathrm{s}$.

\section{Conclusions}

For bit-rates up to $40 \mathrm{~Gb} / \mathrm{s}$, the synchronization tolerance of a MZI XOR gate is determined by the

(a)

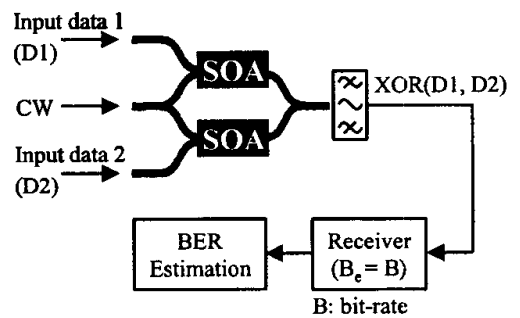

(b)

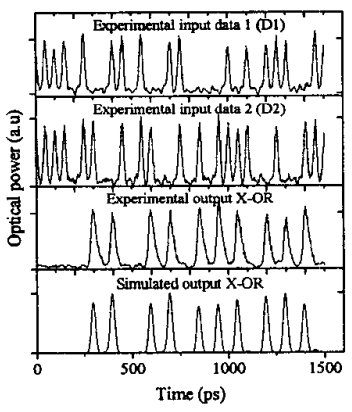

CThAAl Fig. 1. a) Schematic of MZI as an $X O R$ gate, including receiver. b) Experimental 20 $\mathrm{Gb} / \mathrm{s}$ input signals, resulting XOR (from ${ }^{2}$ ), and corresponding simulated XOR signal.
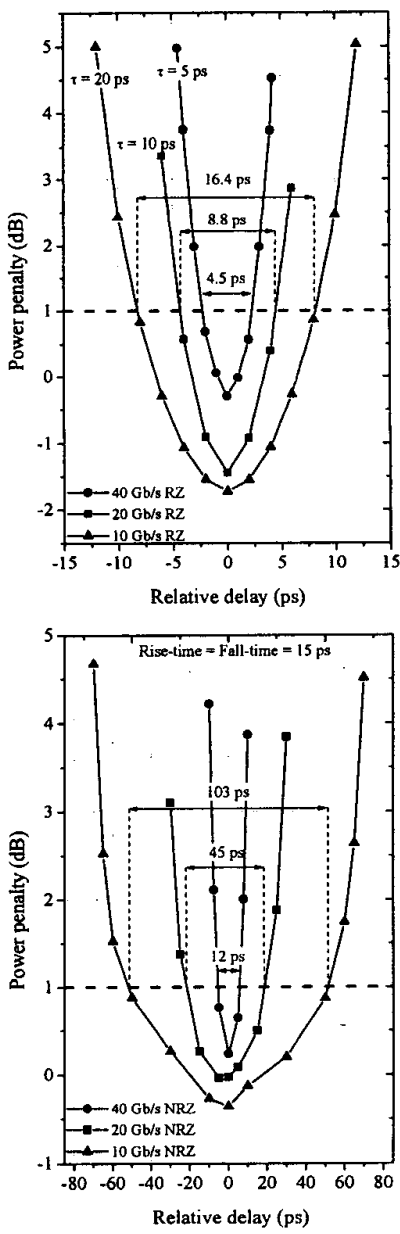

CThAA1 Fig. 2. Power penalty versus synchronization delay for a) RZ format and b) NRZ format.

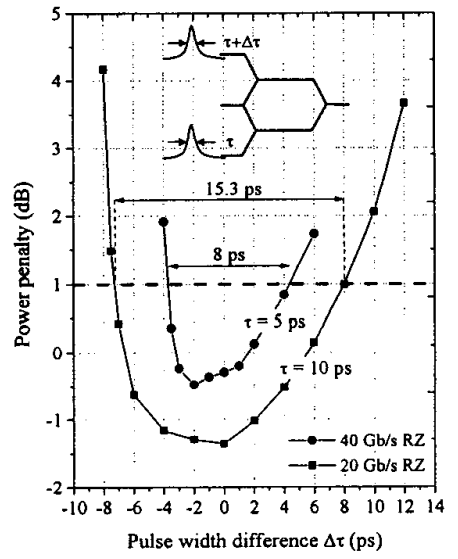

CThAAl Fig. 3. Power penalty versus difference in pulse width between the two data signal.

pulse width for RZ format. For the NRZ format the tolerance decreases as the rise/fall-time approaches the timeslot. The gate is found to be very tolerant towards differences in the $R Z$ pulse width. 
References

1. C. Bintjas et al., " $20 \mathrm{~Gb} / \mathrm{s}$ All-Optical XOR with UNI gate", IEEE PTL 12, 834-36 (2000).

2. T. Fjelde et al., "Demonstration of $20 \mathrm{Gbit} / \mathrm{s}$ all-optical logic XOR in integrated SOAbased interferometric wavelength converter", IEE EL. 36, 1863-64 (2000).

3. T. Fjelde et al., "Novel Scheme for Simple Label-Swapping Employing XOR Logic in an Integrated Interferometric Wavelength Converter", IEEE PTL, 13, 750-52 (2001).

4. G. Theophilopolous et al., " $40 \mathrm{GHz}$ All-Optical XOR with UNI Gate", in Techn. Digest OFC 2001, MB2-1.

Suppression of Pattern Distortion in Semiconductor Optical Amplifler by Using Fiber Loop Mirror

K. Chan, C.K. Chan, F. Tong, W. Hung,

L.K. Chen, Information Engineering Dept, The

Chinese University of Hong Kong, Shatin, N.T.,

Hong Kong, China, Email:kchan0@ie.cuhk.edu.hk

\section{Introduction}

Semiconductor optical amplifier (SOA) attracts much interest because of its wide application for in-line amplification. Its attractive features in cluding broad gain bandwidth, compactness, and potentially low cost, make it a promising device for future lightwave networks. However, the fas gain dynamics of the SOA causes waveform distortion and hence limits its practical implementation. Different schemes have been proposed to suppress the waveform distortion, including ligh injection, ${ }^{1}$ shifting the output wavelength, ${ }^{2}$ etc. Here we present a novel scheme to alleviate the waveform distortion in gain-saturated SOAs. Gain variation due to fast gain dynamic of SOA is compensated by an interferometer formed by a simple fiber loop mirror. Over $5-\mathrm{dB}$ enhancement in input power dynamic range is obtained.

\section{Proposed Scheme and Experiment}

The experimental setup is shown in Fig. 1. Light from the DFB laser was modulated by a $\mathrm{LiNbO}_{3}$ modulator using 10-Gbit/s $2^{23}-1$ NRZ PRBS. The optical variable attenuator (OVA) was carefully adjusted for different optical input power to the SOA. The SOA was put in a fiber loop mirror with an offset of $\Delta t$ from the loop center. The reflected signal output from the loop mirror was directed out via an optical circulator (OC). For comparison, a direct amplification experiment was also performed as shown in Fig. 1(a).

For SOA operating in saturation regime, the decrease of carrier density results in gain variation, which not only leads to waveform distortion but also simultaneously causes phase modulation of the signal inside the SOA. In the proposed scheme, as the SOA is located with a certain offset from fiber loop center (as shown in Fig. 1), the clockwise propagating signal enters the SOA earlier and its rising edge experiences much larger gain variation and phase modulation, as compared to that of the counter-clockwise propagating signal, which enters the SOA at a later time. As a result, a large phase difference is present only at rising edge of the two counter-propagating signals. When they are combined again at the $3-\mathrm{dB}$ coupler, destructive interference due to such

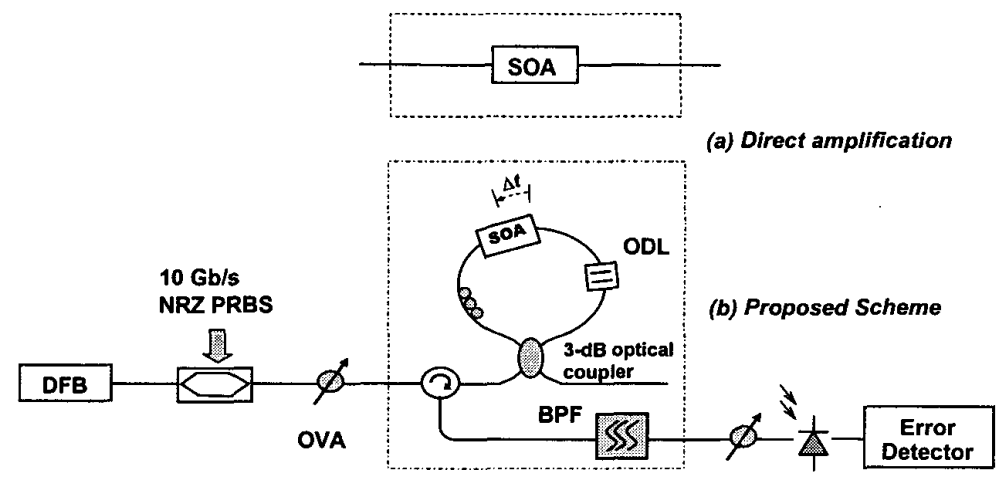

CThAA2 Fig. 1. Experiment setup. OVA: optical variable attenuator; SOA: semiconductor optical amplifier; ODL: optical delay line; BPF: optical bandpass filter. phase difference at the rising edge occurs and this effectively leads to suppression of the waveform distortion at the output of the fiber loop mirror

Fig. 2 shows the pulse pattern from the SOA for (a) direct amplification case and (b) proposed scheme using fiber loop mirror. It was found that

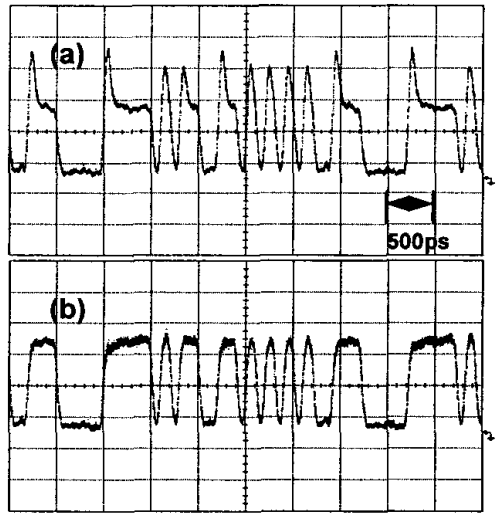

CThAA2 Fig. 2. SOA output waveforms (a) Direct amplification (b) Proposed Scheme. the power variation at the rising edges of " 1 ". was much suppressed by using our proposed scheme. We have also measured the SOA input power $d y$ namic range in both cases and the results were depicted in Fig. 3. The power penalty was obtained at a BER of $10^{-9}$ against different signal input range was extended over $5-\mathrm{dB}$, for a power penalty of 3-dB. The eye diagrams in the insets were captured with input power at $-12 \mathrm{dBm}$.

\section{Summary}

An interferometric approach for pulse pattern efstrated. Suppression of waveform distortion is achieved by using fiber loop mirror. Over $5-\mathrm{dB}$ input power dynamic range enhancement is obtained.

\section{References}

1. K.P. Ho, S.K. Liaw and C. Lin, Electron. Lett., 1996, 32, pp. 2210-2211.

2. J. Yu and P. Jeppesen, JLT, vol 19, 2001, Pp $1316-1326$. powers. It was shown that input power dynamic fect reduction in SOA is proposed and demon-

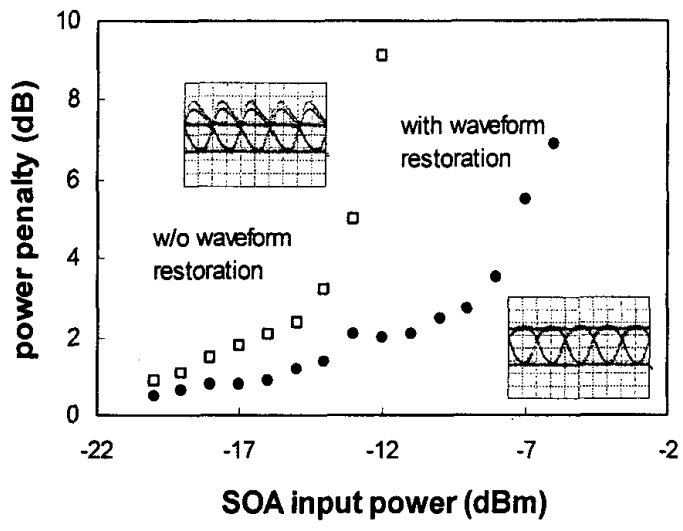

CThAA2 Fig. 3. Power penalty at $10^{-9}$ against input signal power. Inset: eye diagrams for signal input power at $-12 \mathrm{dBm}$. 